\title{
Learning and Thinking Styles Based on Whole Brain Theory in Relation to Emotional Intelligence
}

\author{
Ahmad Mohamed Awad AlGhraibeh \\ Department of Psychology, College of Education, King Saud University, Riyadh, Saudi Arabia \\ Email: gha2hmad@yahoo.com
}

Received 15 April 2015; accepted 1 May 2015; published 12 May 2015

Copyright (C) 2015 by author and OALib.

This work is licensed under the Creative Commons Attribution International License (CC BY). http://creativecommons.org/licenses/by/4.0/

(c) (i) Open Access

\begin{abstract}
Based on Whole Brain Theory, this study explores the relationship between learning and thinking styles and emotional intelligence to determine correlations between the variables and to discover whether they differ according to gender and age groups. Two tests are used: learning and thinking styles based on Whole Brain Theory, and sensory-motor integration. Validity and reliability are tested; correlation coefficient is calculated using Pearson test. Total reliability for learning and thinking styles scored 0.860. Total internal consistency by Cronbach Alpha scored 0.872. Emotional intelligence reliability scored 0.880 , and internal consistency scored 0.920 . The study was conducted on a stratified random (cluster) sample of 753 male and female students, ranging in age from 12 to 16 years, Members of the sample set were enrolled in 13 public schools (7 all-male and 6 all-female schools) within the Irbid first directorate. The results indicated a positive correlation $(40.8 \%)$ between emotional intelligence (emotional assimilation) with upper left brain (henceforth (Q_A)) and learning and thinking styles of the Lower Right Brain (henceforth (Q_C)) and upper right brain (henceforth (Q_D)). Linear correlation showed statistical significant differences between emotional intelligence dimensions test (emotional assimilation and emotional understanding) and Q_D in favor of females. Statistical significant differences are also found between emotional assimilation and Q_A and Q_C in favor of females.
\end{abstract}

\section{Keywords}

Whole Brain Theory, Emotional Intelligence, Learning and Thinking Style

Subject Areas: Neuroscience

How to cite this paper: AlGhraibeh, A.M.A. (2015) Learning and Thinking Styles Based on Whole Brain Theory in Relation to Emotional Intelligence. Open Access Library Journal, 2: e1436. http://dx.doi.org/10.4236/oalib.1101436 


\section{Introduction}

Stimulating the emotional center generates reactions in behavior in the form of gestures and expressions due to the structure of the nervous system. Claude Bernard indicated that arousal of a sensory nerve stimulated the heart, thereby generating a reaction in the brain. The brain in turn reacts to the heart's stimulation, generating responses in both directions, i.e. action-reaction [1]. Emotions are significantly reflected in behavior, providing regular body reaction data and drawing the body's attention to its surroundings. The human body generates data from sense organs and provides the data to the brain. The brain then combines these data points with emotions and logic to produce the thinking process required for optimal performance and decision-making [2]. But, relying on the interaction of these elements may impede the thinking process [3] [4].

Learning and thinking styles provide meaning to our experiences. Learning styles may be divided into: auditory, motor and visual learning. A learner with a dominant auditory style preference may be able to function effectively in other styles. Individuals who flexibly swing from one style into the other while adapting to a problem are considered more efficient in thinking and learning than those who are less flexible [3] [5].

Through information processing individuals who use one part of the brain preferentially over the other, commonly referred to as brain dominance. Brain dominance may also be interpreted from the perspective of the styles used in the process of thinking and learning. The concept of the leading hemisphere is attributed to the neuroscientist John Jackson who is considered to be the origin of brain dominance theory. Many educators at primary, secondary, and even university level have noted the importance of this phenomenon in the process of thinking and learning through the study of correlations among learning and thinking styles and the functions of the two brain hemispheres [6].

There are several ways of considering the brain physiologically. Scientists have divided the brain structures into three functional components: hind-brain, mid-brain and fore-brain. This division was first studied in biology in the 1950s and 1960s. Nevertheless, the division was arbitrary, contributed very little in facilitating our understanding. The following two theories of organization are much more useful and increasingly popular today: the triune brain theory and the left brain/right brain theory [7]. For the purposes of this study the researcher considers Herrmann's Whole-Brain Theory. This theory offers an approach for understanding brain functions through the Four Quadrant Model which presents four modes of learning and thinking based on whole-brain theory; the theory focuses on three key ideas: first, styles are not featured as good or bad nor right or wrong; second, the style shows a preference for mental activity, which is quite different from the efficiency of performing that activity; finally, styles tend to be constant over time [7]. Herrmann explains these styles as follows: Left Mode Thinking Processes is divided into two parts Upper Left Quadrant or what is referred to as Q_A. This style features the individual preference of activities such as analyzing, dissecting, figuring out, solving problems logically, and getting facts. In making decisions, the individual relies on logic based on certain assumptions, combined with the ability to perceive, verbalize, and express things precisely. Additionally, the individual prefers reducing the complex to the simple and the unclear to the clear [7]. He tends to avoid emotions altogether, he works in isolation, appears arrogant, and tends to discount the importance of human feelings always. Thus, his thinking is linear, but he is smart in his own way.

Herrmann [7] further notes the Lower Left Quadrant is symbolized by (Q_B). A Q_B features a person who has rules, adheres to them and to what has worked before. However, he fights progress and does not accept change. His efficiency has to do with making sure things are done on time and correctly; he focuses on one thing at a time [3] then moves to another, and his interest is always focused on answers.

Right Mode Thinking processes include two parts as well. Lower Right Quadrant which is referred to as Q_C. A Q_C is featured as a sponge that sops experience. Similar to Q_A, Q_C is preoccupied with facts associated with emotional trends, he recognizes the mood change the moment it happens and responds to it calmly. He recognizes experience as a fact. There is no time for logic or for theoretical perspective for him [3]. Emotions and spirituality provide him with a sense of belonging to the world, he has an internal instinct of belonging to the spiritual family, and that we are living to help each other; being affectionate and emotional, objective does not matter for him if it conflicts with humanitarian purposes unifying us in groups. A Q_C is sentimental, consensual and beautiful, harmony and beauty oriented, poetic, and oriented toward the people and the past.

The second part of Right Mode Thinking, Upper Right Quadrant, referred to as Q_D, features an ambiguous person. His speech relies on metaphors without providing translations of how these metaphors help in clarifying what he says. This individual thrives on the excitement of new ideas, possibilities, variety, oddities, incongrui- 
ties, and questions that sound obvious but in fact they go deep to the heart of the matter. He is imaginative, artistic, and quite confusing from time to time. His creativeness functions with the support of Q_A, Q_B, Q_C [7]. Lower quadrants Q_C and Q_B control our emotional responses. Left lower quadrant Q_B seems to work as a nerves organizer of unpleasant emotions, while the right quadrant Q_C is the center of our negative emotions (fear and aggression). The frontal left quadrant stops, or discourages negative emotional explosions [8] [9]. The Amygdala in turn stores emotional remembrances of events.

The brain has two memories: one for normal events and a second for emotionally charged events [4] [10]. Emotions stem from the Latin verb "Movere": meaning to move away and refers to the fact that every emotion has a tendency of doing something [11]. Emotions are motives of our actions basically; they are the immediate plans to deal with the evolution in our being as humans. Responses toward emotions reflect four basic types: fear, sadness, anger and joy, the rest of emotions consist of the four responses mentioned combined together [3].

Two brains, regarding functional differences, also exist Male Differentiated, and Female Differentiated [12]. Studies on differences between male and female brains focused on the different size of the brain between genders at birth. Male brain size at birth is larger than the female, the head circumference being approximately $2 \%$ larger in male than in female [13].

Thinking functions among females spread in a wide area of the brain which reduces learning difficulties, while among males it spreads in limited areas because of the size of corpus callosum, which increases the likelihood of learning difficulties among them. Serotonin increases more among females $(20 \%-30 \%)$ times than among males. This prevalence is associated with fear, shame and low self-confidence, as well as with aggression and recklessness, suicidal, alcoholism, depression and agitation. There are differences between males and females in the structure of hypothalamus specifically in the preoptic area that controls Mating Behavior; it has been found that this area is larger among males, and has higher cell counts than females. But the corpus callosum size connecting the two brain hemispheres is larger in females and is more developed [3].

Psychologists argue about the age of which brain specialization develops and grows [14]. Specifically, does this process occur at birth or in later years [15]? Some advocate researchers of the evolutionary theory believe that myelin formation corresponds with childhood development. Piaget classified (cited in [16]) age groups into:

a) Sensorimotor stage ( 0 - 2 years old): in this stage the child uses motor activity with the surrounding and forms ideas about how to deal with it. At this stage, myelin deposits on motor and visual systems in the brain.

b) Pre-operational stage ( 2 - 7 years old): at this stage a child cannot think of abstract things, it needs a physical environment for learning. At this stage, myelin deposits on the brain language regions.

c) Concrete operational stage (7 - 11 years old): the child can understand some abstract issues and solve some problems, but he learns through physical and working environments. At this stage, myelin deposits on thinking and cognition regions.

d) Formal operational stage (11 - 15 years old): at this stage a teenage can perform abstract thinking, the level of his recognition becomes similar to the adults recognition. At this stage, myelin deposits on higher-order thinking and problem-solving and decision making regions of the brain.

Among brain researchers, it is agreed that the impulse that propagates through neurons depends on myelin deposits. That is to say, the larger the myelin sheath is on axons, the easier the communication between neurons becomes. Additionally, usage frequency of networks between neurons increases the amount of myelin deposited on the axons, which explains the importance of redundancy and recitation. Fluidity of impulse propagating through neural network correlates significantly with myelin sheath that insulates the axons allowing correlation between neurons to be easier, accessible and quick [17].

\subsection{Review of Literature}

If one assumes that the twentieth century science is based on brain researches, then hemisphericity relationship with emotional intelligence becomes a necessity. Malley [18] examined the relationship between hemisphericity and individual responses. A total of 254 college students from California University completed the Learning and Thinking test by Torrance and Reynolds, in addition to an emotional response measure. Students were asked to (1) think of a relaxing situation and enjoy it for 5 minutes (time required to obtain a base reading); (2) visualize a very upsetting event (stressor 1: 1 minute); (3) leave the scene of the upsetting event and relax (1 minute); (4) count backwards silently from 900 in 7's (stressor 2: 1 minute); (5) begin a loud from where they left off in the counting (stressor 3: 1 minutes) and (6) relax as much as possible (1 minute). Stressors situations recorded 0.70, 
0.71, and 0.43 respectively, indicating that there was little linear correlation. Likewise, there was little linear correlation between brain function and gender and among brain function, rest level, and gender.

Schlesinger [9] explored the relationship between the two hemispheres and musical improvisation in the light of demographic variables. Subjects included 100 males, who were right handed, aged 17 - 49 years old with an average age of 22.8 years, were enrolled in seven programs, four years long in Massachusetts, New York, and New Jersey. The study focused on two hypotheses to explain the relationship between thinking and musical styles. The first hypothesis predicted that the right hemisphere was positively correlated with musical preference. The second hypothesis predicted that the left hemisphere was negatively correlated with music. The results supported the first hypothesis only.

Mikkelson, Farinelli and Valley [19] examined brain dominance effect on expressive and sensitive skills and emotional control across different genders. A sample of 466 individuals (178 female and 288 male), aged 18 47 years in southwestern United States participated in the study. Subjects were classified into; whole dominance or anomalous dominance. It was hypothesized that brain dominance would interact to affect the expressive, sensitivity skills and emotional control. It was found that hemispheric dominance negatively affected both emotional control and emotional expression. In particular, it was found that whole dominance males scored higher in emotional expression and lower in emotional control, while females scored lower in emotional expression and second higher in emotional control.

Wheeler, Davidson and Tomarken [20] studied individuals emotional reactions, and asymmetry between the two hemispheres. They hypothesized that individual differences are related to the variation in activation of the left and right frontal brain regions. Subjects of the study were 90 females, aged 17 - 21 years, from Wisconsin USA. Baseline brain electrical activity from subjects on two occasions was recorded three weeks apart. Immediately following the second recording subjects were exposed to emotional film clips. For subjects whose frontal asymmetry was stable across the three week period, greater left frontal activation was associated with more intense reports of negative affect in response to the negative film clips [20].

Breitenstein, Daum and Ackermann [21] conducted a study to examine the differential contribution of cortical and sub-cortical brain structures in emotional processing. Forty six individuals participated in the study from Tubingen in Germany. A standardized measure of emotional perception (Tubingen Affect Battery) was used. The findings imply involvement of the frontostriatal circuitry in emotional processing.

Pickens, Field and Nawrocki [22] recorded the EEG of 10 pre-school children in Florida, while exposing them to film clips of an imaginary child going through happiness, sadness, anger and fear situations. Variance analysis revealed the existence of asymmetry in the anterior lobe. The left anterior lobe revealed an active emotional in all clips, this style of activation of the left lobe may represent a trend or a positive general mild response even in negative emotional situations. Children showed explicit facial expressions and some evidence of lips movement while seeing negative clips. No evidence was found when activating right frontal lobe.

Borod, Bloom, Brickman, Nakhutina and Curko [23] conducted a study in (2002) in New York, as a literature review of the neural mechanisms. The study explored three theoretical issues. The first issue presented pertained to the neuropsychology of emotion, including parameters of emotional processing, emotional domains, and hypotheses regarding hemispheric specialization for emotion. The second issue reviewed was hemispheric asymmetries of emotion in terms of the processing mode (perception and expression) and communication channel (facial, prosodic-intonational, and lexical-verbal). The third issue described the recent findings identifying the role of the right hemisphere in emotional processing. The study concluded by supporting the new data with findings from the general literature, providing added support for the right-hemisphere emotion hypothesisb [24].

Sergerie, Lepage and Armony [25] described the role of the Amygdala on enhanced emotional memory as encoding and retrieval. Functional Magnetic Resonance Imaging (F-MRI) event related and remembering facials with different emotional expressions, both encoding and recognition was examined. It was concluded that amygdala activation is associated with the correct encoding and retrieval of fearful faces. A comparison between the two phases revealed that the right side correlated with Emotional Memory Formation, while memory retrieval relied on the left side. Therefore, this study supported the notion of variance between the two hemispheres in emotional memory.

Mandell and Pherwani [26] examined the predictive relationship between emotional intelligence and gender. Subjects of the study were 32 Northeast USA managers. A significant predictive relationship was found between emotional intelligence and gender in favor of females.

Petrides, Martin and Furnham [27] explored emotional intelligence differences among males and females. 
Two hundred sixty individuals from Britain, mostly Caucasians, were subjected to the emotional intelligence test. Females scored higher than males on emotional intelligence dimensions. However, when all dimensions scorings were combined together, males showed that they believe their emotional intelligence is greater than females. Most of the correlations between emotional intelligence dimensions and self-evaluation were statistically significant, leading to the conclusion that individuals can evaluate their own emotional intelligence. Correlations between dimensions scores and self-evaluations were generally greater for males than for females. Results proved that gender is a statistically significant predictor of self-evaluation of emotional intelligence.

Wang [28] conducted an experiment to investigate gender differences in response to public service advertising with sad emotional appeal vs. rational appeal. One hundred and ninety three undergraduates attending two universities in Hong Kong were recruited to voluntarily participate in the experiment. The sample was composed of 100 full time students (age ranges 18 to 24) and 93 part-time nontraditional students (age ranges from 25 to 50). An Empathic Emotion measurement was administered. Results showed that females showed more favorable attitude towards helping when exposed to the sad emotional appeal advertisement than the rational appeal advertisement. However, males showed no significant differences in attitude to helping in the two conditions. Such gender differences in effectiveness of sad emotional appeal were found to be mediated by advertisement evoked empathic emotions [28].

Alumran and Punamaki [29] examined gender and age differences in emotional intelligence (EI) and coping styles amongst a sample of Bahraini adolescents. Participants were 312 Bahraini adolescents, who were randomly selected from intermediate schools, and secondary schools, and students of the University of Bahrain. Participants completed the Bar-On Emotional Quotient Inventory (EQ-i-YV) and Youth Version-Short Form. Results showed that gender, but not age, was significantly associated with emotional intelligence among Bahraini adolescents.

Hassan, Sulaiman and Ishak [30] investigated the correlations of emotional intelligence with gender and age. A sample of 223 students from different ages in Malaysia participated in the study. Schutte-Self Report of emotional intelligence (SSRI) was administered. No statistically significant differences in emotional intelligence were found in ages 13 - 16. However, there was a statistical significant difference in emotional intelligence level among all students in favor of females.

\subsection{Statement of the Problem}

Recognizing that similar brains do not exist, is it possible to input the same data in two different brains and expect the same result? Educational researchers and school curricula have focused more attention on the left brain and processes associated with it as logical and linguistic intelligence. The right brain functions receive decreased attention, although it is considered the visual and musical intelligence center which "Gardner" called for, and is the special ability center as stated by "Thirston." Additionally, this lack of attention seems inadequate given that the right brain regions excel in emotional aspects of learning.

Researchers disagree on the correlation type between the two brains and between quadrants and whether it is a replacement or wholeness (integration) correlation. There is also disagreement on the correlation of either right brain and its quadrants or left brain and its quadrants or both brains with respect to emotional intelligence. To the best of the researcher's knowledge this issue has not been dealt with. The current study is an attempt to explore student's preferences in using one half of the brain over the other, and the brains correlation level with emotional intelligence [28]-[30] Students of ages (12, 14, and 16) years were involved in the study. In particular, this study attempts to answer the following questions.

What type of correlation exists between learning and thinking styles based on whole-brain theory and emotional intelligence test and its dimensions?

Are there significant correlation differences $(\alpha=0.05)$ due to age and gender groups?

\subsection{Significance of the Study}

Studying learning and thinking styles based on whole-brain theory and styles association with emotional intelligence adds an important dimension to the educational and developmental procedures. This emphasis is designed to increase understanding among educationalists of social and emotional adjustment. Additionally, it adds an important focus on the relationship between brain chemistry, emotional intelligence and academic performance. The most important aspect of emotional education of children is an actual change of brain chemistry and more 
accurately to teach children ways to control the functions of the brain and to provide clear indications to educators about the type of training the student needs. Moreover, it is of equal importance to introduce educational materials that develop emotional intelligence skills such as self-awareness, social responsibility, self-management, empathy skills, positive listening, accepting others, making friends, developing a trend towards the welfare of others, decision-making, and how to overcome negative emotions.

The study was designed to identify differences between male and female preferences of brain quadrants and emotional intelligence, specifically in the age group (12 - 16 years old). This age group is important and dynamic of the study in that it constitutes early adolescence where such characteristics as the desire for independence, getting rid of restrictions, identity search, physical changes and emotional fluctuations, may contribute to the finding of causes for the differences. A desired consequence of the study was to promote the development of appropriate educational and psychological programs for both genders based upon their underlying differences. Results pertaining to preferences usage of one quadrant over the other, gender differences correlation with emotional intelligence were not conclusive. The need for more studies prevails in order to further explicit this correlation.

\subsection{Difinitions of Terms}

Learning style based on whole-brain theory means individual usage of one quadrant of the brain (learning style: Q_A; Q_B; Q_C; Q_D) in mental processes. It is measured by individuals' performance on learning and thinking styles test [7].

Q_A learning and thinking style is the individuals' tendency to rely on upper left quadrant functions while processing information, it is measured by the number of items responses on the test of learning and thinking styles based whole brain theory.

Q_B (lower left brain) learning and thinking style is the individuals' tendency to rely on lower left quadrant functions while processing information, it is measured by the number of items responses on the test of learning and thinking styles based whole brain theory.

Q_C learning and thinking style is the individuals' tendency to rely on upper right quadrant functions while processing information, it is measured by the number of items responses on the test of learning and thinking styles based whole brain theory.

Q_D learning and thinking style is the individuals' tendency to rely on lower right quadrant functions while processing information, it is measured by the number of items responses on the test of learning and thinking styles based whole brain theory.

Emotional Intelligence: performance on emotional intelligence test.

\subsection{Limitations of the Study}

The study is limited to male and female students of ages 12_13, 14_15, and 16_17 from Irbid First Directorate primary schools. It is limited to psychometric characteristics of emotional intelligence and learning and thinking styles tests based on whole-brain theory and statistical analysis used. Therefore the results of the study are valid for generalization.

\subsection{Variables of the Study}

Independent variables:

1. Age groups (12_13,14_15, 16_17) years.

2. Gender.

Dependent variables:

1. Learning and thinking styles based on whole-brain theory Q_A, Q_B, Q_C, and Q_D.

2. Emotional intelligence.

\section{Experiment Design}

\subsection{Participants}

The study was conducted on a stratified random (cluster) sample of (753) male and female students, their age 
group was (12 - 16) years; they were enrolled in 13 public schools (7 all-male, 6 all-female schools) at Irbid first directorate (Table 1).

\subsection{Instruments}

The researcher used three tests; learning and thinking styles based on whole-brain theory, emotional intelligence test, and sensory motor integration test.

Learning and thinking styles based on whole-brain theory is a test derived from Herrmann's Brain Dominance Instrument "HBDI"; it consists of 120 items based on whole-brain theory. Chi revised and developed the test to adjust it to Chinese students; it consisted of 60 items describing a series of learning activities which students preferred in their learning process divided on four brain quadrants, 15 items to test each quadrant. The test is divided into the four styles as Chi describes [3] [7]:

1. Q_A: learning and thinking style preferred by students featuring A quadrant "upper-right brain".

2. Q_B: learning and thinking style preferred by students featuring B quadrant "lower-left brain".

3. Q_C learning and thinking style preferred by students featuring $C$ quadrant "lower-right brain"

4. Q_D: learning and thinking style preferred by students featuring D quadrant "upper-right brain”.

\subsection{Validity and Reliability}

Eight professors, at the Department of Counseling \& Educational Psychology at Yarmouk University, verified logical validity of items before administering the test and agreed upon its validity. Additionally, the test was verified by administering it on a pilot sample composed of three classes (students ages 12, 14, 16 and no.192) other than the sample of the research (one class for each age group). The test-retest was administered two weeks apart. Reliability on Pearson correlation coefficient scored (0.860) on the overall test, and its scores on separate dimensions were as follows: (Q_A: .7360; Q_B: .7000; Q_C: .7760; Q_D: .7940). Internal consistency (Cronbach Alpha) scored 0.872 on the overall test, and for the dimensions it scored (Q_A: 0.744 Q_B: 0.720; Q_C: 0.676; Q_D: 0.773)

Total score of students' responses on each quadrant were calculated and classified as follows (little 0 - 4.99) (average 5 - 9.99) (Large 10 - 15).

Adolescents Multifactor Emotional Intelligence Scale developed by Mayer, Salovey, Caruso (referred to in Kafafi \& Aldawash, [31]) was used to measure the ability to identify meanings of emotions and its relationship to others and its logical justifications. The instrument also measures the ability to recognize emotions and their significance with the ability to manage this emotional cognition in one's self as well as others. The test consists in its final form of four dimensions: Perceiving Emotions, Assimilating Emotions, Understanding Emotions, and Managing Emotions

Mayer, Salovey, and Caruso (referred to in Kafafi \& Aldawash [31]) verified fact, criterion, construct and content validity. Eight professors, at the Department of Counseling \& Educational Psychology at Yarmouk University, verified the logical validity of items before administering it, and gave few comments about items wording which the researcher corrected.

Mayer, Salovey \& Caruso (referred to in Kafafi \& Aldawash [31]) measured stability using Cronbach Alpha coefficient, overall stability scored 0.94, Perceiving emotions (0.93), Assimilating Emotions (0.89), Under-

Table 1. The distribution of the participants according to gender and age.

\begin{tabular}{|c|c|c|c|c|c|}
\hline \multirow{2}{*}{ Gender } & \multirow{2}{*}{ Statistics } & \multicolumn{3}{|c|}{ Age } & \multirow{2}{*}{ Total } \\
\hline & & $12-13$ & $14-15$ & $16-17$ & \\
\hline \multirow{2}{*}{ Male } & No. & 123 & 132 & 115 & 370 \\
\hline & Percentage & 16.3 & 17.5 & 15.3 & 49.1 \\
\hline \multirow{2}{*}{ Female } & No. & 130 & 124 & 129 & 383 \\
\hline & Percentage & 17.3 & 16.5 & 17.1 & 50.9 \\
\hline \multirow{2}{*}{ Total } & No. & 253 & 256 & 244 & 753 \\
\hline & Percentage & 33.6 & 34.0 & 32.4 & 100.0 \\
\hline
\end{tabular}


standing Emotion (0.82) and Managing Emotions (0.85). Reliability on Pearson correlation coefficient scored on overall (0.88), Perceiving Emotions (0.804), Assimilating Emotions (0.89), Understanding Emotions (0.761) and Managing Emotions (0.728) Internal consistency (Cronbach Alpha) scored (0.92) on the overall test, Perceiving Emotions (0.923), Assimilating Emotions (0.851), Understanding Emotions (0.753) and Managing Emotions (0.740). Test scores were calculated and classified into (very high: 80.0 - 100.0, high: 60.0 - 79.99, average: 40.0 - 59.99, low: 20.0 - 39.99, and very low: 0.0 - 19.99)

\subsection{Statistical Analysis}

Correlation coefficient between learning and thinking styles based on whole-brain theory and between emotional intelligence test and its dimensions were calculated. Statistical difference between both coefficients of emotional intelligence correlation with its dimensions and of learning and thinking styles based on whole-brain theory was calculated using the equation difference between correlations.

\section{Results}

Pearson correlation coefficients were used to determine the relationship between emotional intelligence test and its dimensions with each of the 4 leaning and thinking styles. Review Table 2.

Based on Table 2 it appears that there was a positive significant correlation at the level $(\alpha=0.05)$ between emotional intelligence test and its dimension of understanding emotions from one part, and learning and thinking styles based on the whole brain theory (Q_A, Q_C, Q_D) on the other part. It also showed no significant correlations between emotional intelligence test and its dimensions and learning and thinking styles $(\alpha=0.05)$ (12 of which were negative, 5 were positive) and all of them had a very low correlation or zero-correlation.

Correlation coefficients between learning and thinking styles based on whole-brain theory and the emotional intelligence test and its dimensions were also calculated. Pearson correlation was used to calculate these correlations with respect to gender after, and then coefficients were converted into their correspondent z- Fisher values. Finally, the equation of difference between correlation coefficients of two independent samples was applied as shown in Table 3.

Based on Table 3, a significant difference may be observed $\alpha=0.05$ in the linear correlation between emotional intelligence with understanding emotions and assimilating emotions one hand with learning and thinking styles of upper left brain Q_D on the other hand, in favor of females.

Moreover, Table 3 shows a significant difference $(\alpha=0.05)$ in linear correlations between dimensions and of assimilating emotions on one hand and both learning and thinking styles based on whole-brain theory of Q_A upper left brain and Q_C lower right brain on the other hand, in favor of females. Finally, it was revealed that no significant difference $(\alpha=0.05)$ exists between the rest of linear correlations among emotional intelligence test and its dimensions and other learning and thinking styles.

Correlation coefficients between emotional intelligence and its dimensions and the four learning and thinking styles were also calculated. Pearson equation was used to calculate correlations with respect to age and then they were converted into their correspondent z-Fisher values. V-correspondent values revealed the significant differences of the correlations according to age groups; the value was compared with Chi square on two freedom classes $\left(\chi_{\mathrm{df}=2}^{2}=5.99\right)$ as shown in Table 4 .

Table 4 shows no statistical differences $(\alpha=0.05)$ in the linear correlations between emotional intelligence test and its dimensions with learning and thinking styles according to age groups.

Table 2. Linear correlation between EI dimensions and learning styles based upon whole brain theory.

\begin{tabular}{ccccc}
\hline Emotional Intelligence (EI) Dimensions & Q_A & Q_B & Q_C & Q_D \\
\hline Perceiving Emotions & -0.03 & -0.02 & -0.04 & -0.06 \\
Assimilating Emotions & 0.09 & 0.07 & 0.12 & 0.10 \\
Understanding Emotions & 0.00 & -0.01 & 0.02 & 0.00 \\
Managing Emotions & -0.05 & -0.03 & -0.03 & -0.03 \\
Total Score & -0.02 & -0.01 & 0.00 & -0.03 \\
\hline
\end{tabular}


Table 3. Results of z-Fisher values of gender differences in correlations between: intelligence test dimensions and modes of learning and thinking based on whole-brain theory.

\begin{tabular}{|c|c|c|c|c|c|c|}
\hline EI Test & Thinking \& Learning Styles & Gender & Correlation & No & Z & Statistical Significance \\
\hline \multirow{8}{*}{$\begin{array}{c}\text { Perceiving } \\
\text { Emotions }\end{array}$} & \multirow{2}{*}{ Q_A } & Male & -0.032 & 370 & \multirow{2}{*}{-0.144} & \multirow{2}{*}{0.443} \\
\hline & & Female & -0.021 & 383 & & \\
\hline & \multirow{2}{*}{ Q_B } & Male & -0.029 & 370 & \multirow{2}{*}{-0.367} & \multirow{2}{*}{0.357} \\
\hline & & Female & -0.002 & 383 & & \\
\hline & \multirow{2}{*}{ Q_C } & Male & -0.055 & 370 & \multirow{2}{*}{-0.370} & \multirow{2}{*}{0.356} \\
\hline & & Female & -0.028 & 383 & & \\
\hline & \multirow{2}{*}{ Q_D } & Male & -0.084 & 370 & \multirow{2}{*}{-0.715} & \multirow{2}{*}{0.237} \\
\hline & & Female & -0.032 & 383 & & \\
\hline \multirow{8}{*}{$\begin{array}{l}\text { Assimilating } \\
\text { Emotions }\end{array}$} & \multirow{2}{*}{ Q_A } & Male & 0.029 & 370 & \multirow{2}{*}{-2.074} & \multirow{2}{*}{0.019} \\
\hline & & Female & 0.179 & 383 & & \\
\hline & \multirow{2}{*}{ Q_B } & Male & 0.050 & 370 & \multirow{2}{*}{-1.090} & \multirow{2}{*}{0.138} \\
\hline & & Female & 0.129 & 383 & & \\
\hline & \multirow{2}{*}{ Q_C } & Male & 0.063 & 370 & \multirow{2}{*}{-1.707} & \multirow{2}{*}{0.044} \\
\hline & & Female & 0.186 & 383 & & \\
\hline & \multirow{2}{*}{ Q_D } & Male & 0.034 & 370 & \multirow{2}{*}{-1.901} & 9כ0 0 \\
\hline & & Female & 0.171 & 383 & & $0.0 \angle 3$ \\
\hline & Q_A & Male & -0.020 & 370 & -0852 & 0197 \\
\hline & & Female & 0.042 & 383 & 0.002 & 0.157 \\
\hline & $\mathrm{P}$ & Male & -0.019 & 370 & -0761 & בר? 0 \\
\hline Understanding & Q & Female & 0.037 & 383 & -0.701 & 0.223 \\
\hline Emotions & 0 & Male & -0.028 & 370 & & \\
\hline & Q L & Female & 0.075 & 383 & -1.399 & 0.081 \\
\hline & $\mathrm{O} D$ & Male & -0.097 & 370 & -2652 & 0004 \\
\hline & 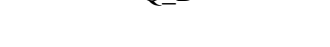 & Female & 0.097 & 383 & & \\
\hline & OA & Male & -0.026 & 370 & 0956 & 0170 \\
\hline & $Q_{2} \mathrm{~A}$ & Female & -0.096 & 383 & 0.550 & $0.1 / 0$ \\
\hline & $\mathrm{O} B$ & Male & -0.022 & 370 & 0630 & 0262 \\
\hline Managing & & Female & -0.069 & 383 & & \\
\hline Emotions & & Male & -0.013 & 370 & & \\
\hline & $2+0$ & Female & -0.045 & 383 & 0.431 & בנב.ב. \\
\hline & D & Male & -0.040 & 370 & -0236 & 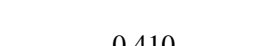 \\
\hline & Q & Female & -0.024 & 383 & -0.220 & 0.410 \\
\hline & 0 A & Male & -0.030 & 370 & & סריר \\
\hline & $Q_{-}$ & Female & 0.003 & 383 & -0.443 & $0.3<0$ \\
\hline & O B & Male & -0.021 & 370 & -0.458 & 0334 \\
\hline Emotional & Q & Female & 0.012 & 383 & 0.450 & 0.024 \\
\hline Intelligence (EI) & 0 & Male & -0.035 & 370 & 1 & 010 \\
\hline & Q L & Female & 0.031 & 383 & -0.901 & 0.184 \\
\hline & D ת & Male & -0.090 & 370 & 1797 & 0036 \\
\hline & & Female & 0.041 & 383 & & \\
\hline
\end{tabular}


Table 4. V results of age differences in correlation coefficients between emotional intelligence dimensions and learning and thinking styles based on whole-brain theory.

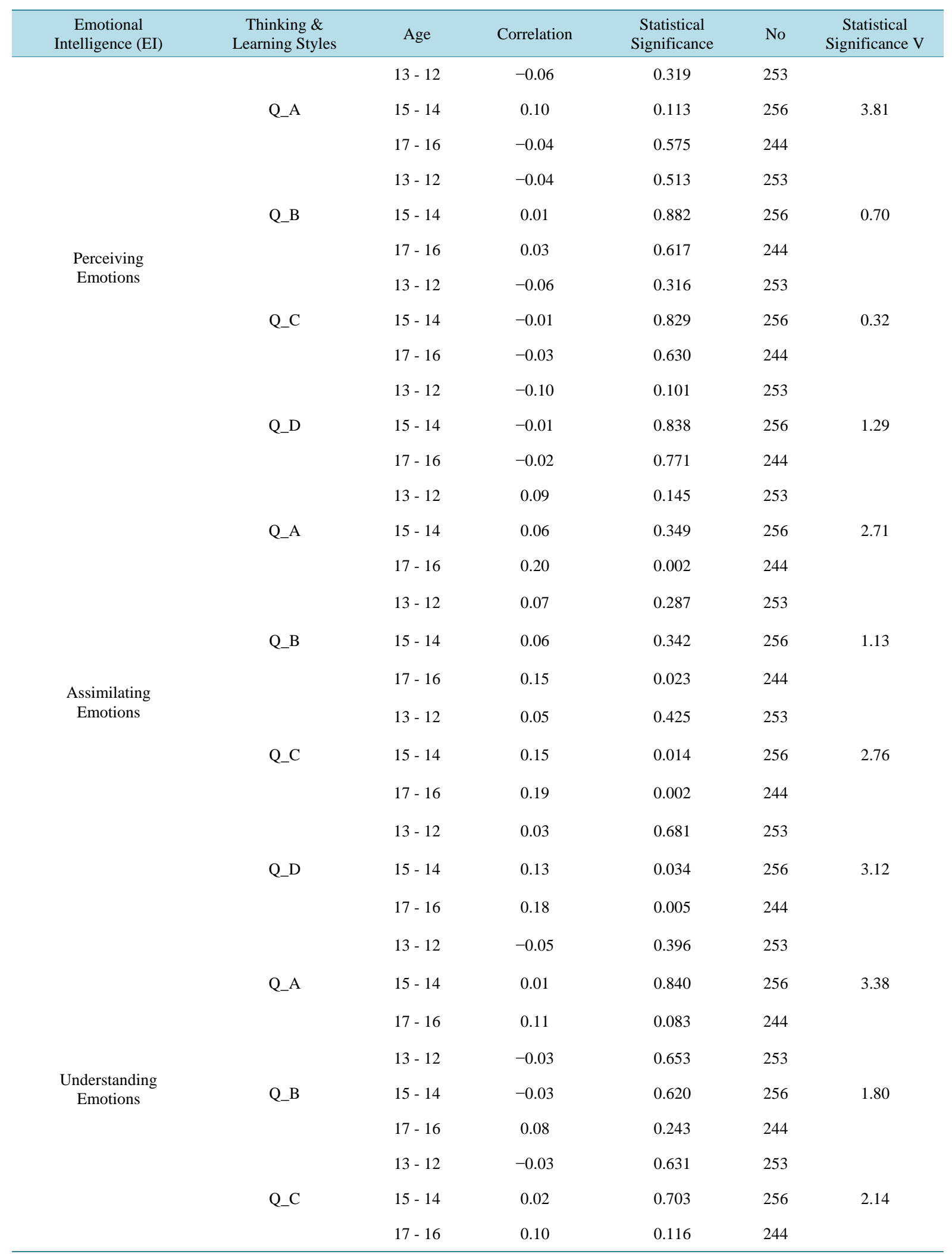




\section{Continued}

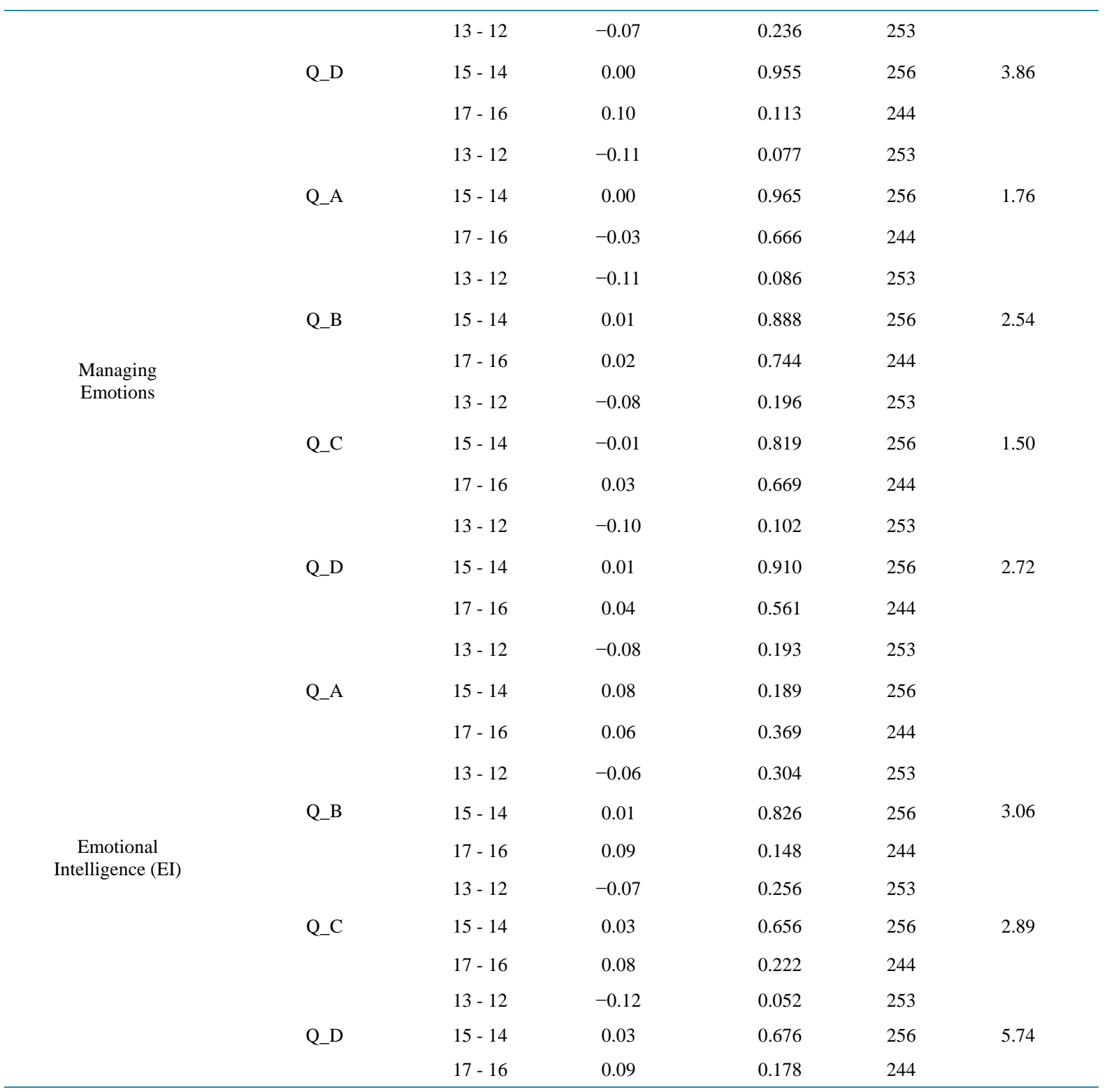

\section{Discussion}

Right hemisphere is referred to as the emotion-driven brain, whereas the left hemisphere is referred to as the logic-driven brain. The logic-driven brain is utilized to understand and think deeply about conceived input. The two hemispheres harmonize together to help us manage and understand lives. The emotion-driven brain supplies the logic-driven brain with the data needed for mental operations, while the logic-driven brain helps filter input to the emotion-driven brain. Thus, emotiveness and logic are inseparable, logical thinking is as important for emotion as emotion is for logical thinking. When emotiveness exceeds the balance point, then a case of emotion-driven brain dominates [8].

Bruck [32] defines specific functions for each hemisphere. For example, the right hemisphere is responsible for emotional reaction and responses such as laughter and forgiveness. This brain dimension is called the 'feminine hemisphere'. However, research-conducted on the damages suffered by one (or both) of the hemispheres showed that both parts can handle not only the type of emotional reaction, but also the potentiality of having positive or negative tendency towards the emotional response. Left frontal lobe for example represents a positive 
emotional response or tendency, whereas right frontal lobe is associated with the negative emotional response [20]. According to the results of the current study, we may notice the dominancy of the lower and upper right mode of learning and thinking. These two parts represent the right hemisphere which is known to be emotion-driven.

The right hemisphere is specifically concerned with the brain activities that are related to intuition, feeling, creativity, and imagination. It is also responsible for processing data and visualized materials as well as musical materials, not to mention emotional stimuli. This is why it is called the sensual, intuitive, or emotional hemisphere. Moreover, this part is more in charge of recognizing faces; it is the humoristic part, and it is connected with amygdala all the time in order to control the emotive responses and initiating proper reactions [14].

Tucker indicates that both hemispheres have their contributions in Human emotive expressiveness and more studies must be conducted to know more about theoretical and methodological factors before asserting the correctness of any assumption [33]. Some studies have shown that individuals rely on the brain as a whole to execute their emotive responses rather than relying on one hemisphere over another, music analysis for example takes place in the left hemisphere along with verbal utterances analysis, whereas musical tasting and enjoyment takes place in the right hemisphere.

Upper left mode of learning and thinking comprises special capacities and features such as logical judgments and rational decisions. These capacities steer this mode of learning and thinking towards realism and discipline [7] [34] and this indeed could improve the emotive side in the individual.

Females have higher percentage of serotonin (also known as mood substance) than males. This substance is responsible for feeling of rest and relaxation. Since females are more likely subject to mood fluctuations, due to serotonin increasing and decreasing, activation associated with emotion centers in females is usually found. Serotonin is a type of neurotransmitter which stimulates emotive reactions by transmitting emotive neuro-messages from the brain throughout the body. It helps fight depression and stress, plays a role in determining body temperature, blood pressure, digestion, sleeping, and helps children overcome all types of stress. Excess secretion of this substance is usually accompanied by shortage in feelings of hatred and aggressiveness. A small smile is all that is needed to manufacture this substance. When smiling, the face muscles contracts, blood turns colder, and blood pressure decreases. This justifies the solution we tend to give to our children for stressful situations: "you only need to smile and everything will be just right". So, this solution is totally right and effective, supporting the notion that small things might have great results.

Corpus callosum in females is $3 \%-10 \%$ larger and more developed than its correspondence in males. Fibers in the corpus callosum connect parallel lobes as well as non-parallel lobes in each hemisphere. This yields a regular network of communication which supports the integral functionality of the brain.

The stereotypical image of females (sensitivity and hyper-sympathy) is heavily attached to societal expectations. Maturity in females helps the completion of cortex development which is typically associated with warmth, coziness and selflessness. Mothers are Q-C when they give birth to their children and Q-B when they protect and defend them. They are more interested than males in the humanistic side of feelings and emotions and they are more likely to possess a tendency for the arts and understanding body language. They are also typically better in recalling faces and memorizing texts, and they tend to use intuition to solve problems.

The results of emotional intelligence test according to Table 2 above are correlated significantly with the learning and thinking styles based on the whole brain theory with Q_A, Q_C, and Q_D. The correlation differences between emotional intelligence and emotional understanding and assimilation are found to be statistically significant in the learning and thinking styles of the upper left brain and in the Q_D in favor of females. The correlation between assimilating emotions dimensions and learning and thinking styles based on whole-brain theory of Q_A upper left brain and Q_C lower right brain were significant and in favor of females.

Research results in this domain are merely at the beginning stage. However, other studies and research can explain how emotive operations depend on neuro-physiological activities and the functions of the hemispheres.

This result agrees with Pickenss, Field and Nawrocki [22] who note that emotion processing is concentrated in the hemispheres, especially in the right lobe, and emotion processing is concentrated in the frontal lobes (left and right). But it disagrees with Malley's [18] study which states that no connection exists between brain dominance and emotions.

\section{Recommendations}

The present study comes out with the following major recommendations. First, non-curriculum material in- 
tended to promote emotional intelligence should be incorporated into scholastic syllabi. These materials should target self-consciousness, social responsibility, self-management, and how to accept the others. Secondly, curriculum planning should be reconsidered, and right-hemispheric students must be allocated to specific activities. Moreover, gender differences associated with emotional intelligence should be taken into account in order to design appropriate psychological programs which go with the specificity of both genders. Finally, cooperation between neurologists and educational researchers in designing training programs to serve the educational process based on the results reached by brain related studies.

\section{References}

[1] Darwin, C. (2005) The Expression of the Emotions in Man and Animals. Trans. Magdi Melegy, Supreme Council of Culture, Cairo.

[2] Christianson, S.-A. (1992) Emotional Stress and Eyewitness Memory: A Critical Review. Psychological Bulletin, 112, 284-309. http://dx.doi.org/10.1037/0033-2909.112.2.284

[3] Al Ghraibeh, A. and Al-Zahrani, A. (2013) Learning and Thinking Styles Based on Whole Brain Theory in Relation to Sensory-Motor Integration. Research in Neuroscience, 2, 1-10

[4] LeDoux, J.E. (1994) Emotion, Memory, and the Brain. Scientific American, 270, 50-57. http://dx.doi.org/10.1038/scientificamerican0694-50

[5] Sally, P. and Georg, D. (2001) Left Brain, Right Brain: Perspectives From Cognitive Neuroscience. 5 Edition, W. H. Freeman and Company/Worth Publishers, New York.

[6] Kamel, M. and As-Safi, A. (1995) Impact of Interaction between Learning and Thinking Style and Anxiety on Academic Achievement among University Students. King Saud University Journal of Educational Sciences and Islamic Studies, 7, 275-313.

[7] Herrmann, N. (1995) The Creative Brain. Quebecor Printing Book, USA.

[8] Goleman, D. (2000) Emotional Intelligence Trans. Laila Al-Jabali, Knowledge World, Kuwait.

[9] Schlesinger, J. (1985) Hemisphericity, Field Dependence Independence, and Preference for Musical Improvisation: Relationships among Cognitive and Musical Styles. Proquest Dissertation, New York University, New York, 135B (AAT NO. 8521989).

[10] Davidson, R. and Sutton, S. (1995) Affective Neuroscience: The Emergence of a Discipline. Current Opinion in Neurobiology, 5, 217-224. http://dx.doi.org/10.1016/0959-4388(95)80029-8

[11] Reeve, J. (1997) Understanding Motivation and Emotion. Harcourt Brace College Publishers, Orland.

[12] Springer, S.P. and Deutsch, G. (1989) Left Brain, Right Brain. Freeman, New York.

[13] Jensen, E. (2005) Teaching with the Brain in Mind. 2nd Edition, Association for Supervision and Curriculum Development, Alexandra.

[14] Temple, C. (2002) The Brain: An Introduction to the Psychology of the Human Brain and Behavior (Penguin Science). Penguin Books, UK.

[15] Alawneh, S. (2004) Psychological Human Development Childhood. Dar Al-Furqan, Amman.

[16] Wordsworth, B. (1989) Piaget’s Theory of Cognitive and Affective Development Paperback. Psychology Press, Amazon.

[17] Abdel Qawi, S. (2001) Neuropsychology: Foundations and Evaluation Methods. UAE University Press, UAE, Al Ain.

[18] Malley, N. (1982) The Relationship between Hemisphericity and the Response of Individuals to Induced Stress. Proquest Dissertation, University of Pittsburgh, Pittsburgh, 129B (AAT 8303626).

[19] Mikkelson, A., Farinelli, L. and Valley, A. (2006) The Influences of Brain Dominance and Biological Sex on Emotional Expressivity, Sensitivity, and Control. Communication Quarterly, 54, 427-446. http://dx.doi.org/10.1080/01463370601035947

[20] Wheeler, R., Davidson, R. and Tomarken, A. (1993) Frontal Brain Asymmetry and Emotional Reactivity: A Biological Substrate of Affective Style. Psychophysiology, 30, 82-89. http://dx.doi.org/10.1111/j.1469-8986.1993.tb03207.x

[21] Breitensteina, C., Daumc, I. and Ackermannd, H. (1998) Emotional Processing Following Cortical and Subcortical Brain Damage: Contribution of the Fronto-Striatal Circuitry. Behavioural Neurology, 11, 29-42. http://dx.doi.org/10.1155/1998/579029

[22] Pickens, J., Field, T. and Nawrocki, T. (2001) Frontal EEG Asymmetry in Response to Emotional Vignettes in Preschool Age Children. International Journal of Behavioral Development, 25, 105-112. http://dx.doi.org/10.1080/01650250042000140 
[23] Borod, J., Bloom, R., Brickman, A., Nakhutlna, L. and Curko, E. (2002) Emotional Processing Deficits in Individuals with Unilateral Brain Damage. Applied Neuropsychology, 9, 23-36. http://dx.doi.org/10.1207/S15324826AN0901_4

[24] Gasquoine, P.G. (1997) Emotional, Cognitive, and Motivational Deficits in Compensation-Seeking, Suspected Brain Injury Cases. Applied Neuropsychology, 4, 99-106. http://dx.doi.org/10.1207/s15324826an0402_2

[25] Sergerie, K., Lepage, M. and Armony, J. (2006) A Process-Specific Functional Dissociation of the Amygdala in Emotional Memory. Journal of Cognitive Neuroscience, 18, 1359-1367. http://dx.doi.org/10.1162/jocn.2006.18.8.1359

[26] Mandell, B. and Pherwani, S. (2003) Relationship between Emotional Intelligence and Transformational Leadership Style: A Gender Comparison. Journal of Business and Psychology, 17, 387-404. http://dx.doi.org/10.1023/A:1022816409059

[27] Petrides, K., Martin, G. and Furnham, A. (2004) Estimates of Emotional and Psychometric Intelligence: Evidence for Gender-Based Stereotypes. The Journal of Social Psychology, 144, 149-162. http://dx.doi.org/10.3200/SOCP.144.2.149-162

[28] Wang, C. (2008) Gender Differences in Responding to Sad Emotional Appeal: A Moderated Mediation Explanation. Journal of Nonprofit \& Public Sector Marketing, 19, 55-70. http://dx.doi.org/10.1300/J054v19n01_03

[29] Alumran, J. and Punamaki, R. (2008) Relationship between Gender, Age, Academic Achievement, Emotional Intelligence, and Coping Styles in Bahraini Adolescents. Individual Differences Research, 6, 104-119.

[30] Hassan, A., Sulaiman, T. and Ishak, R. (2009) Philosophy Underlying Emotional Intelligence in Relation to Level of Curiosity and Academic Achievement of Rural Area Students. Journal of Social Sciences, 5, 95-103. http://dx.doi.org/10.3844/jssp.2009.95.103

[31] Kafafi, A. and Aldawash, F. (2006) Multi Factor Emotional Intelligence Scale for Adults and Adolescents. AngloEgyptian Library, Cairo.

[32] Bruck, K. (1979) Introduction to Human Anatomy. Harper \& Row, New York.

[33] Sifft, J. (1991) Educational Kinesiology: Empowering Students and Athletes through Movement. Physical Education, 5, 28-31.

[34] Jensen, E. (1998) Teaching with the Brain in Mind. ASCD, Alexandria. 